\title{
Desakralisasi Simbol Politheisme dalam Silsilah Wayang: Sebuah Kajian Living Qur'an dan Dakwah Walisongo di Jawa
}

\author{
Syamsul Bakhri, Ahmad Hidayatullah
}

IAIN Pekalongan

Naskah diterima 30 Maret 2019, direvisi 9 Mei 2019, disetujui 2 Juni 2019

Abstract An Wayang is an adoptive creation from the Ramayana Mahabharata epic in the past that certainly full of Hinduism value. Descriptive qualitative research use library study approach aims to find out the desacralization of symbols of polytheism through the composition of wayang lineages. Those data validity is obtained by triangulating data sources, By integrating data from journals and books on wayang lineages then analyzed by the acculturation theory of Koentjaraningrat. The results showed that Walisongo was the creator and composer of wayang in new shape. Gap between Islam and Hinduism, especially on the theological side, polytheism raises the desacralization of symbols of polytheism, through the formation of a new lineage of the wayang. The change also changes the value of the epic Ramayana Mahabharata story that is centered on Trimurti before, to the nasab of the Prophet Sis then the Prophet Adam which is a representation of the symbol of God monotheism that does not have children, as writen in Al Qur'an; Changes in the wayang lineage and da'wah were carried out persuasively by Walisongo without causing any conflict in the community, even bloodshed.

Keywords: Desakralization, Politheism, Wayang, Living Qur'an, Da'wah

Abstrak Wayang merupakan karya adoptif dari epos Ramayana Mahabharata yang pada masa sebelumnya tentu sarat akan ajaran Hinduisme. Penelitian kualitatif deskriptif dengan pendekatan studi kepustakaan ini bertujuan untuk mengetahui desakralisasi simbol-simbol politheisme melalui gubahan silsilah wayang. Validitas data diperoleh dengan cara triangulasi sumber data, dengan mengintegrasikan data dari jurnal dan buku mengenai silsilah wayang lalu dianalisis dengan teori akulturasi dari Koentjaraningrat. Hasil penelitian menunjukkan bahwa Walisongo sebagai kreator dan penggubah wayang dalam bentuk baru; Benturan nilai antara ajaran Islam dengan Hindu, utamanya pada sisi teologis, yakni politheisme memunculkan desakralisasi simbol-simbol politheisme, melalui gubahan silsilah wayang yang baru. Perubahan itu sekaligus merubah nilai cerita epos Ramayana Mahabharata yang terpusat pada Trimurti, menuju pada 
silsilah Wayang yang berujung pada nasab Nabi Sis kemudian Nabi Adam yang merupakan representasi simbol tauhid bahwa tuhan tidak beranak dan diperanakan sesuai dengan ajaran yang ada di Al-Qur'an; Perubahan silsilah wayang dan dakwah dilakukan secara persuasif oleh Walisongo tanpa sedikitpun memunculkan konflik di tengah masyarakat apalagi sampai adanya pertumpahan darah.

Kata Kunci: Desakralisasi, Politheisme, Wayang, Living Qur'an, Dakwah.

\section{A. PENDAHULUAN}

Wayang yang dikenal sebagai sebuah masterpiece kebanggaan masyarakat Jawa, tidak akan pernah terlepas dari nilai Hinduisme -yang berasal dari India- yang melatar belakanginya (Dwiandiyanta, dkk, 2012: 96). Wayang sebagai sebuah karya adoptif sebagaimana disampaikan oleh Rassers yang menyatakan bahwa pertunjukan wayang di Jawa bukanlah ciptaan asli orang Jawa. Pertunjukan wayang di Jawa, merupakan tiruan dari apa yang sudah ada di India, utamanya dari segi pementasan yang menekankan pada seni memainkan bayang-bayang dari sebuah benda, Rassers dalam (Supriono, dkk, 2008: 12). Wayang secara aspek penceritaan diketahui mengambil sebagian besar dari kisah Ramayana dan Mahabharata (Slamet, 2014: 18). Menurut mitologi India, Ramayana dan Mahabharata tersebut masuk ke dalam referensi sejarah, hal ini karena apa yang termaktub dalam dua kisah tersebut benarbenar terjadi di India. Semisal setting Negara Hastina pada zaman Prabu Bharata disebut Pratistana, terdapat di kaki gunung Himalaya dan terdapat dalam lembah Madya-desa yang berada di tepi sungai Gangga, dan sungai-sungai yang berhulu padanya, seperti sungai Jamuna dan Serayu. Negara Indrapastha (Ngamarta, Amarta, yaitu Negara kekuasaan Prabu Yudhistira) sekarang masuk wilayah Delhi. Negara Madra (Madraka, Mandraka, yaitu Negara kekuasaan Prabu Salya) yang kini bernama Madras. Negara Langka (Alengka, yakni Negara kekuasaan Rahwana) sekarang bernama Srilangka (Padmosoekotjo, 1979: 15).

Realitas lain yang terdapat pada kedua sumber tersebut - Ramayana dan Mahabharata- keduanya bukan hanya sekadar epos sejarah, melainkan juga memiliki muatan teologis Hindu. Fakta itu bisa dilihat dalam kitab suci agama Brahma -Hindu-yang terbagi dalam dua kategori, akan ditemukan dua epos itu menjadi bagian dari kitab suci umat Hindu itu sendiri. Pertama, Sruti, yakni kitab yang berisikan ajaran 
yang langsung diwahyukan Brahma (Zat Tunggal Maha Pencipta) kepada rishi (orang suci), yaitu kitab suci Veda (Sou'yb, 1996: 27). Kedua, Smriti, yakni setiap tradisi (ucapan, perbuatan, tulisan) yang mengandung ajaran seorang rishi (orang suci) atau ajaran seorang acharya (guru) atau pun ajaran avatar (ingkarnasi-ilahi) seumpama Krishna dan lainnya. Himpunan kitab yang termasuk dalam Smriti itu diantaranya termasuk Brahmanas, Upanishads, Mahabharata, Bhagavadgita, Ramayana, Purana, dan Lainnya (Klostermaier, 2003: 176).

Bicara tentang teologi Hindu, maka satu ajaran yang tidak bisa dilepaskan di dalamnya adalah perihal adanya keyakinan kepada para Dewa. Dewa-Dewa dalam mitologi Hindu diyakini sebagai manifestasi, sinarnya Tuhan dalam fungsi tertentu. Oleh karena kekuasaan dan fungsi Tuhan demikian luas dan dalam, serta rumit, maka Tuhan mewujudkan diri dalam wujud dewa-dewa. Dengan kata lain, dewadewa adalah ciptaan Tuhan seakan-akan dewa-dewa itu terpisah dengan Tuhan, padahal sesungguhnya mereka adalah bagian integral dari kebesaran Tuhan (Jendra, 2003: 109).

Saat monarki Hindu-Jawa mulai surut pada awal abad ke-15, mulailah terlihat pengaruh Islam masuk dalam kesenian wayang. Kenyataan ini wajar sebab keruntuhan kekuasaan Hindu terjadi salah satunya ditengarai oleh ekspansi Islam, meski faktor besar lain adalah adanya konflik para bangsawan Hindu-Jawa yang turut mempersuram masa depan kerajaan-kerajaan tersebut, semisal Majapahit (Sutioyono, 2013: 4). Raden Patah -yang seorang muslim- dalam hal ini seringkali dikaitkan oleh sumber lokal sebagai faktor runtuhnya Majapahit. Tetapi hasil penelitian mutakhir menunjukkan bahwa keruntuhan Majapahit lebih banyak karena konflik internal keluarga kerajaan. Kerajaan Bintoro Demak yang bercorak Islam inilah yang kemudian muncul pada akhir abad XV bersamaan dengan surutnya Majapahit (Purwadi, dkk: 2006: $\mathrm{xv}$ ).

Fase awal kekuasaan Demak Bintoro ini kemudian menandai babak baru perkembangan wayang. Wayang sebagai sebuah media hiburan yang sudah begitu digemari masyarakat -baik anggota kerajaan maupun awam- pada era ini harus dihadapkan dengan kenyataan bahwa wayang dinilai Hinduistik, animistik, dan bahkan diharamkan karena tidak sesuai dengan ajaran Islam (Sudjarwo, dkk, 2010: 51).

Menurut Suhardjono sejak awal ada masalah yang signifikan antara tradisi wayang dengan Islam. ada beberapa elemen wayang yang dinilai 
tidak tepat dengan budaya Islam. Sebagai contoh bentuk wayang yang menampilkan figur manusia dan beberapa narasi tidak mengandung nilai-nilai keislaman, dan kisah-kisah tentang Dewa dan Dewi yang dinilai sebagai berhala (Suhardjono, 2016: 233).

Munculnya doktrin itu seketika membuat genre teater ini -wayangbahkan barada di ambang kepunahan. Namun atas keputusan Walisongo bentuk permainan bayangan ini justru dalam bentuk barunya menjadi sangat populer. Wayang pada era ini bukan hanya bisa bertahan, namun lebih dari itu wayang mengalami salah satu transformasi artistik paling menarik dalam sejarah teater (Yousof, 2010: 87). Fenomena ini kemudian memunculkan konsolidasi melalui perpaduan prinsip estetika yang berasal dari dua budaya besar, yakni Hindu dan Budha. Pertemuan dua unsur besar, ini membuat wayang mau atau tidak memiliki kandungan dari masing-masing ajaran agama tersebut (Sumuh dalam Yousof, 2010: 87). Keduanya tentu menjadi bagian yang tidak terpisahkan dari kesenian wayang baik secara subtantif maupun tersirat. Terlebih Islam, yang dalam hal ini sebagai poros terakhir yang menampung dan memanfaatkan wayang sebagai media guna membumikan ajaran Islam di tanah Jawa memiliki andil besar dalam terjadinya reinterpretasi simbol dari ajaran-ajaran sebelumnya. Tidak hanya sampai disitu, perubahan tersebut pada giliranya justru menjadi media desakraliasi simbol politheisme yang bertentangan dengan tauhid yang menjadi inti ajaran Islam. Proses tersebut kemudian dibangun melalui berbagai hal, salah satunya melalui silsilah wayang itu sendiri. Alhasil tahap ini kemudian menjadi era baru kesenian wayang dengan Walisongo sebagai aktor sekaligus kreator utamanya.

\section{B. METODE PENELITIAN}

Penelitian kualitatif deskriptif dengan pendekatan studi kepustakaan ini bertujuan untuk mengetahui desakralisasi simbol-simbol politheisme melalui gubahan silsilah wayang. Validitas data diperoleh dengan cara triangulasi sumber data. Dengan mengintegrasikan data dari jurnal dan buku mengenai silsilah wayang lalu dianalisis dengan teori akulturasi dari Koentjaraningrat. Proses penelitian dengan kajian kepustakaan ini dilakukan dengan mengidentifikasi dan menemukan informasi yang relevan mengenai silsilah wayang di Jawa lalu dianalisis dengan teori akulturasi, kemudian dikembangkan, dan diekspresikan sesuai gagasan peneliti. Penelitian kepustakaan harus memanfaatkan judul subjek, 
memanfaatkan buku-buku yang ada di perpustakaan, pencarian kutipan dan pencarian catatan terkait, dan membuat daftar pertanyaan sesuai kata kunci (Mann, 2005).

\section{HASIL DAN PEMBAHASAN}

\section{Politheisme dalam Hindu}

Politheisme berasal dari kata Yunani polys dan theos. Polys berarti beberapa atau banyak, theos berarti Tuhan. Politheisme adalah paham yang mengimani dan memuja banyak tuhan dan dewa (Hardjana, 1993: 25). Politheisme dalam konteks realitas agama di dunia, merupakan satu teologi yang sering kali dikaitkan dengan agama Hindu. Agama ini sendiri secara spesifik merupakan agama yang tidak dikenal satu sosok pendiri sebagai pusat pembawa wahyu sebagaimana dalam agama lain (Rinehart, 2004: 1). I Wayan Suja berpendapat mengenai asal-usul agama Hindu sebagai berikut (Jendra, 2003: 4):

Kata 'Hindu' semula diberikan oleh orang-orang Persia terhadap wilayah di lembah sungai Shindu. Kedatangan orang-orang Yunani

berikutnya, menyebut Hindu dengan Indoi, dan orang-orang Barat mengatakan India. Sementara penduduk setempat menyebut keyakinan mereka Sanatana Dharma, yang berarti dharma yang kekal, abadi, tanpa awal dan akhir (anadi ananta). Kebenaran yang diajarkan adalah kebenaran universal yang tidak dibatasi oleh ruang dan waktu, sebagaimana disebutkan dalam Rg Veda VI. 24. 7, "Tuhan Yang Maha Esa tidak akan menjadikan dia tua, bulan dan demikian pula hari”.

Sementara menurut teori sejarah, Hindu dimulai 4.000 tahun yang lalu ketika sekelompok suku Arya ke Indo-Eropa yang berkulit terang menyerang India Utara. Ketika suku Arya ini pindah ke Lembah sungai Indus/ Shindu, mereka berbaur dengan pribumi, berbagai budaya, tradisi, ritual, simbol dan mitos. Dan yang unik dari pembauran ini adalah bahwa setiap kelompok berperan dan menerima pandangan (Samovar, 2015: 160). Maka tidak salah kalau Samad mengatakan dari seluruh agama yang masih hidup mungkin agama Hindu adalah yang tertua. Agama ini adalah sinkretisme yang dibentuk dari kompromi antara berbagai jenis agama dan kebudayaan di anak benua India. Dua aliran agama yang bercampur dalam agama Hindu, yakni Dravida dan Indo-Aria (Samad, TT: 15). 
Ajaran agama Hindu didasarkan pada asumsi bahwa dunia yang dapat disentuh, dilihat, bukan satu-satunya realita. Sebaliknya, merak percaya ada realita lain yang mengarah pada pertumbuhan rohani serta mengungkap sifat alami kehidupan, pikiran, dan Jiwa. Umat Hindu percaya bahwa dunia secara materi hanya bisa dinikmati sementara waktu. Sedangkan kebahagiaan sejati adalah nirwana (Samovar, 2015: 161).

Mengenai konsep Tuhan, Hindu yang erat dengan polytheisme, nyatanya sepanjang sejarah telah menyatakan beberapa perspektif tentang sifat ketuhanan atau realitas tertinggi; juga pada monotheisme bahkan henotheisme (meyakini satu Tuhan namun tanpa menyangkal ada kekuatan besar yang lain) (Rinehart, 2004: 1). Secara spesifik menurut ajaran Veda Tuhan/Brahman diyakini tidak berkelamin tertentu dan tidak mempunyai usia tertentu. Tuhan itu berjenis kelamin netral, tidak maskulin, tidak feminis, tidak banci, tidak bayi, tidak kanakkanak, tidak dewasa, dan tidak juga tua. Dengan kata lain jenis kelamin dan usia segalanya ada pada diri Tuhan (Jendra, 2003: 104-105). Jain dan Kussman dalam menyimpulkan konsep Brahman, bahwa ia adalah penguasa tertinggi, filsuf yang absolut, pemilik kebahagiaan, melampaui batas etis dan metafisika. Dan pandangan dasar Hindu mengenai Tuhan adalah Maha Besar, Maha Mengetahui dan Maha Penyayang (Samovar, 2015: 162). Pengejawantahan konsep Tuhan dalam Hindu itu sendiri lebih kerap disebut dengan konsep keyakinan terhadap Dewa.

Bukan hanya dalam mitologi Hindu, Dewa menurut berbagai agama dan sistem kepercayaan, diyakini sebagai personifikasi dari suatu kekuatan atau makhluk gaib. Umumnya dewa merupakan manifestasi kekuatan kosmik yang dicipta pada awal penciptaan alam dan ditugaskan sebagai pengendali salah satu aspek alam misalnya dewa langit dan dewa matahari (Ensiklopdeia Umum Untuk Pelajar, 2005: 26). Adapun dalam Hindu, kata Dewa -Deva dalam bahasa India- berasal dari akar kata div (bahasa sankrith) yang memiliki makna sinar. Deva/Dewa adalah sebutan untuk Tuhan dalam mitologi India. Keyakinan terhadap para Dewa yang terdapat dalam kitab Veda dan Purana memiliki konotasi politheistik Svami Danaya Saraswati bahwa kata deva mempunyai sepuluh makna leksikal, yakni: 1) bermain,; 2) menaklukan; 3) aktivitas pada umumnya; 4) kemuliaan; 5) penghormatan; 6) menyenangkan; 7) kerinduan; 8) tidur; 9) keindahan; 10) kemajuan (Jendra, 2003: 108). 
Dewa-dewa dalam mitologi Hindu adalah manifestasi, sinarnya Tuhan dalam fungsi tertentu. Oleh karena kekuasaan dan fungsi Tuhan demikian luas dan dalam, serta rumit, maka Tuhan mewujudkan diri dalam wujud dewa-dewa. Dengan kata lain, dewa-dewa adalah ciptaan Tuhan seakan-akan dewa-dewa itu terpisah dengan Tuhan, padahal sesungguhnya mereka adalah bagian integral dari kebesaran Tuhan (Jendra, 2003: 109). Konsep ketuhanan yang ada dikenal istilah Trimurti, yaitu Dewa terdiri dari Brahma, Wisnu, dan Siwa. Mereka bukanlah dewa yang berdiri sendiri tetapi merupakan tiga aspek yang berbeda dari Tuhan (Hyang Widi Wasa). Lain halnya dengan Budha, di mana Dewa merupakan makhluk surga atau alam luhur yang tampak oleh manusia biasa. Dewa sama dengan manusia dan makhluk yang lain, yaitu lahir, mati, kembali dan terbebas dari karma (Ensiklopdeia Umum Untuk Pelajar, 2005: 26).

Berdasarkan keterangan di atas, tentu tidak berlebihan ketika Dewa dalam artikel ini diimplementasikan sebagai simbol utama agama Hindu. Sebab bicara mengenai agama, mustahil akan terlepas dari pembahasan sistem keyakinan terhadap sesuatu/dzat yang dipuja/disembah. Menyebut Dewa dalam Hindu sebagai simbol utama adalah sama halnya saat mengkaitkan agama-agama lain dengan Tuhan-nya masing-masing, semisal Allah dalam Islam, Trinitas Yesus dalam Nasrani, Yawheh dalam Yahudi dsb. Masing-masing memiliki konsep berbeda dalam sistem berTuhan baik pada tataran keyakinan-spiritual, terlebih dalam tataran ritus-keagamaan. Satu hal yang tidak terbantahkan adalah, masingmasing agama pasti menempatkan 'Tuhan' dalam posisi paling suci dan ini bersifat absolute.

\section{Struktur Silsilah Wayang Purwa}

Sislilah wayang adalah satu hal paling urgent untuk membentuk karakter dan jalur cerita dari karya seni kebanggaan masyarakat Jawa ini. Melalui silsilah, sebenarnya fundamen desakralisasi para Dewa Hindu coba digubah dan disajikan oleh Walisongo secara persuasif. Sebagaimana telah disampaikan sebelumnya, bahwa dalam keyakinan pemeluk Hindu, Dewa adalah simbol tertinggi dari aspek spiritualitas mereka. Memberi silsilah pada sesembahan mereka, secara tegas tentu seolah ingin mengatakan 'setidaknya' para Dewa ini dilahirkan dari dzat yang lebih besar. Wajarnya, semua pemeluk agama akan tersinggung dengan ungkapan semacam ini. Faktanya berbicara lain, alih-alih 
tersinggung -apalagi sampai angkat senjata-, Walisongo justru membuat mereka menikmati proses 'desakralisasi' tersebut. Pencapaian luar biasa, bahkan hingga kini prestasi itu belum -dan bisa jadi tidak akanterpecahkan dalam blantika dakwah di Nusantara. Silsilah para dewa dalam berbagai serat yang masyhur, yakni Layang Kanda, Layang Purwakanda, dan Layang Arjunasasrabahu meletakkan para Dewa Hindu dan karakter Dewa lain (yang baru dalam dunia wayang) pada garis keturunan Nabi Adam, yakni melalui jalur Nabi Sis (Padmosoekotjo, 1979: 26) Berikut secara detail bagan silsilah wayang yang masyhur (Sudjarwo, dkk, 2010: 218:219):

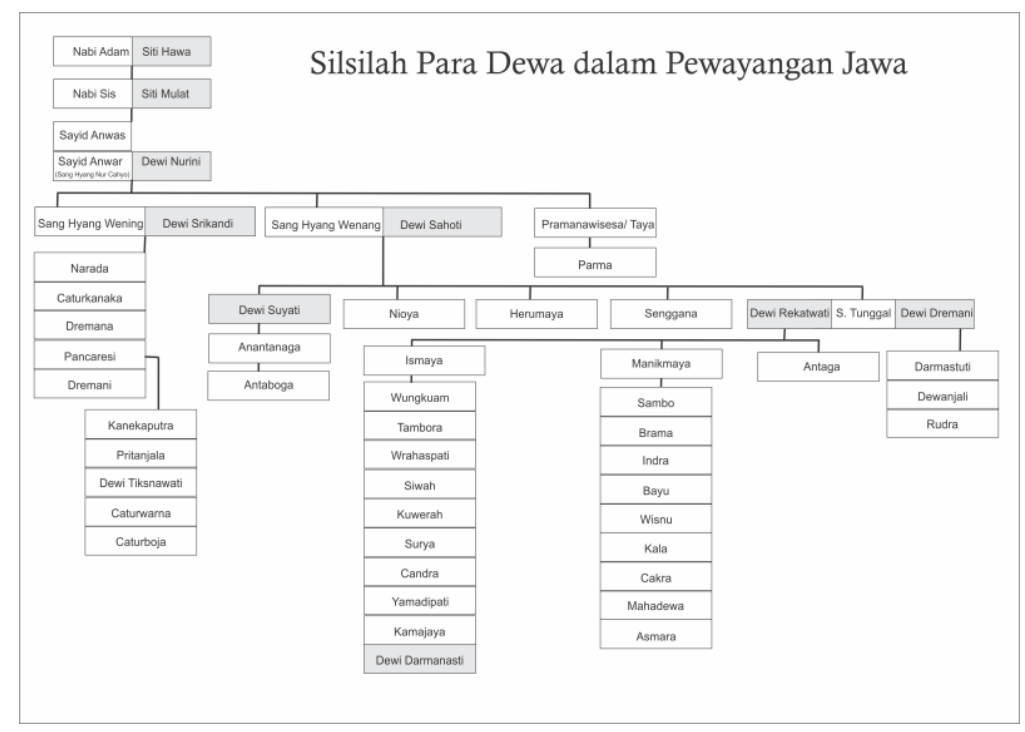

Silsilah di atas tentu berbeda dengan filsafat Adwaita, di mana Dewa tertinggi dalam teologi Hindu, yakni Brahma, Siwa dan Wisnu diyakini sebagai manifestasi dari Brahman -dikenal dengan konsep Trimurtiyang bergelar sebagai sang pencipta (Kapalaye, 2010: 99-100).

Trimurti dalam Hindu berbeda dengan konsep Trinitas dalam teologi Nasrani. Konsep manifestasi dalam Trimurti seakan menekankan pembagian tugas kepada tiga Dewa tersebut, yakni Brahma sebagai Dewa Pencipta, Wisnu sebagai Dewa Pemelihara dan Siwa sebagai Dewa Perusak (John and Ryan, 2006: 453). Ketiganya memiliki peranan sebagai pemangku tugas utama para dewa, kemudian berkembang menjadi tugas pokok Trimurti diemban oleh lima dewa, Sembilan dewa, sebelas dewa, 33 dewa, 333 dewa (Jendra, 104-113). 


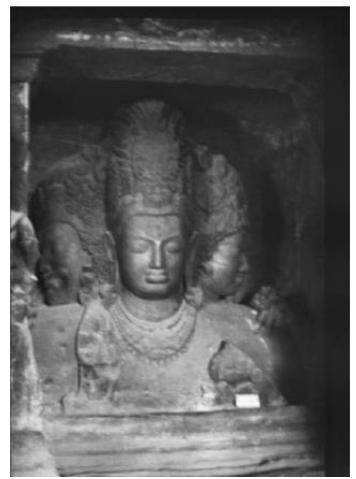

Gambar 1. Patung Trimurti, Sumber: Encyclopedia of World Religion, Ensyclopedia of Hinduism, (2006)

Berbeda dengan Hindu, wayang menampilkan silsilah para Dewa berada di bawah garis keturunan Nabi Adam. Adam sendiri merupakan tokoh yang ada dalam kitab-kitab agama samawi. Kitab Kejadian, Perjanjian Baru dan Kitab Suci Al-Qur'an meyakini Adam sebagai manusia pertama yang diciptakan oleh Tuhan. Pemaparan mengenai kisah Adam dan Hawa memiliki versi yang berbeda-beda diantara agama-agama Abrahamik -Islam, Krtisten dan Yahudi- ini (Dragon, 2016: 1).

Al-Qur'an menyebut nama Adam AS sebanyak 25 kali. Surah alBaqarah berbicara tentangnya dalam ayat 31-37, surah Ali Imran dalam ayat 33 dan 59, surah al-Maaidah dalam ayat 27, surah al-A'raf dalam ayat 11-172, surah al-Isra' dalam ayat 61 dan 70, surah al-Kahfi dalam ayat 50, surah Maryam dalam ayat 58, surah Thaha dalam ayat 115-121, dan surah Yasin dalam ayat 60 (Ilyas, 2016: 5).

Namun pengungkapan kisah mengenai Adam beraneka ragam. Terkadang disebutkan nama, dan sifatnya seperti dalam surah alBaqarah, al-A'raf, al-Isra' dan al-Kahf. Terkadang hanya disebutkan sifatnya saja, seperti dalam surah al-Hijr dan Shad. Ada juga penjelas dari kisah tersebut, yang kesemuanya dirangkum oleh Deddi Ilyas sebagai berikut (Ilyas, 2016: 8-9):

Pertama, Khalifah pertama yang dijadikan Allah di muka bumi adalah Adam as.yang diciptakan dari tanah liat yakni lumpur hitam yang berubah-ubah. Setelah menjadi kering Allah tiupkan ruh ciptaan-Nya sehingga ia menjadi manusia. 
Kedua, Sujud kepada Adam as. Allah memerintahkan iblis dan malaikat sujud kepada Adam as. sebagai bentuk kemuliaan, (tentu bukan sebagai ibadah). Kemuliaan seseorang makhluk tidak dapat dilihat hanya dari materi penciptaannya yang rendah. Sujudnya malaikat menunjukkan kemampuan manusia memanfaatkan hukumhukum alam, dan keengganan iblis sujud menunjukkan kelemahan manusia dan ketidakmampuannya menundukkan jiwa kejahatan atau bisikan-bisikan kotor yang mengantar kepada perselisihan, permusuhan, dan lainnya.

Ketiga, Keengganan dan kesombongan iblis untuk sujud karena dalih bahwasannya iblis lebih baik dari manusia yang diciptakan dari tanah sedang ia diciptakan dari api yang merupakan materi kedua setelah cahaya untuk menciptakan malaikat.

Keempat, Pengajaran Adam as. mengenai al-asmaa' yang merupakan sumber informasi pengetahuan, menunjukkan bahwa Allah memberi distingsi kepada Adam as. karena ia perlu mengambil faedah dari alasmaa' tersebut sebagai bekal keperluannya kelak.

Kelima, Allah menganugerahi beberapa 'fasilitas' atas pengetahuan yang diajarkan kepada Adam as. seperti menetap di dalam surga, layaknya 'rumah dinas' dan beberapa kemudahan-kemudahan lainnya.

Keenam, makna keseluruhan dari penciptaan Adam as. adalah tidak satupun makhluk Allah yang luput dari pada ujian-Nya. Malaikat dan iblis yang diciptakan masing-masing dari cahaya dan api merupakan materi terbaik yang tetap tidak akan luput dari pada ujian untuk 'sujud' kepada manusia yang bermateri tanah atas intelektualitasnya. Manusia pun tidak lepas dari ujian dalam tarafyang berbeda.

Menurut cerita pewayangan, Adam dan Dewi Kawa (Hawa) memiliki 82 anak, dengan rincian 41 putra dan 41 putri. Kesemuanya lahir secara dhampit (bersamaan) keculai Sis dan Hunun. Ada pun urutan perihal kelahiran ke-82 putra Nabi Adam dan Dewi Kawa adalah sebagai berikut (Padmosoekotjo, 1979: 29-30):

1) Kabil (Kain) dan Alimah, 2) Habil (Abil) dan Daminah, 3) Israil (Abdullah) dan Sarirah, 4) Israwan (Abdurrahman) dan Onah, 5) Basradiwan (Abdulkaris) dan Dayunah, 6) Sis, 7) Yasis dan Ngawis, 8) Sesan dan Ngais, 9) Yasmiyan dan Ramsah, 10) Yanmiyan dan Yasurah, 11) Suryan dan Sirriyat, 12) Amman dan Mahas, 13) Kayumarat (Kayumutu) dan Indunmaras, 14) Akjuja dan Makjuja, 15) Lata dan Ujya, 
16) Harat dan Haruti, 17) Danhab (Kawakil) dan Danhabah (Khawokhiyah), 18) Bantas (Asmakil) dan Bintisah (Asmakiyah), 19) Sus (Asmail) dan Susiyah, 20) Jamrud (Malkhail) dan Jamrudah (Malkiyah), 21) Ajurut (Tamkail) dan Ajrudah (Tamkiyah), 22) Adna (Yanhail) dan Adinah (Yainah), 23) Harna (Harnail) dan Harniyah, 24) Samal dan Samiyah, 25) Ngawail dan Ngawiyah, 26) Astail dan Astiyah, 27) Nurail dan Nuriyah, 28) Nukhail dan Nukhiyah, 29) Nukail dan Nukiyah, 30) Sarkail dan Sarkiyah, 31) Karail dan Kariyah, 32) Dujail dan Jujiyah, 33) Katail dan Katiyah, 34) Arkail dan Arkiyah, 35) Mrihkrail dan Mrihkriyah, 36) Ardabbil dan Ardiyah, 37) Sannail dan Paniyah, 38) Sujail dan Pujiah, 39) Salsail dan Salsiyah, 40) Sahnail dan Sahniyah, 41) Siti Hunun, dan 42) Sahalnail dan Sahalniyah.

Tahap atau garis keturunan pertama Nabi Adam ini kemudian menjadi titik tolak gubahan-gubahan baru cerita wayang. Poros utama penceritaan dalam wayang tidak seperti dalam Islam -yang lebih mengenal hikayat Kabil-Habil dan kemudian menjadi pioneer disyariatkannya ibadah qurban-, melainkan pada sosok Nabi Sis sebagai tali penyambung silsilah para Dewa Hindu pada garis keturunan yang berada di bawahnya.

\section{Akulturasi dan Desakralisasi Politheisme dalam Silsilah Wayang}

Menurut Koentjaraningrat (1977) proses akulturasi yang utama adalah unsur diterimanya kebudayaan asing yang diolah ke dalam kebudayaan sendiri tanpa menyebabkan lenyapnya kepribadian kebudayaan asal. Dengan adanya kontak budaya tersebut, memungkinkan terjadinya proses peniruan dan atau modifikasi dari hasil perturakaran budaya tersebut. Kemudian, sifat meniru bukanlah hal yang tidak mungkin dalam kebudayaan, akan tetapi merupakan sifat dari masyarakat dimanapun juga. Akulturasi dalam penelitian ini terjadi dalam proses perubahan silsilah wayang.

Desakralisiasi, dilihat dari segi bahasa, berasal dari kata sacral, yang berarti suci, keramat, atau angker. Kata ini sepadan dengan kata "demitologisasi", artinya proses pembuangan nilai-nilai mitologis. Jadi, bila demikian kata "desakralisasi" yang dimaksud adalah suatu proses masyarakat dari anggapan atau perilaku mensucikan, mengkeramatkan, membakukan, mengagungkan sesuatu, atau beberapa hal yang sebenarnya tidak suci, tidak keramat, tidak baku, dan tidak agung, namun hal ini tidak dimaksudkan untuk menghapuskan orientasi keagamaan pada hal-hal yang dimaksud tersebut (Parson dalam Ishomiddin, 2018:330).

Sudah menjadi pengetahuan bersama bahwa wayang sebagai media kesenian dan kebudayaan masyarakat Jawa mengalami perubahan besar 
pada era Kesultanan Demak. Salah satu keputusan yang didasarkan pada pertimbangan Sultan Demak berikut para penasehatnya -yang diisi oleh jajaran Walisongo- adalah keberadaan kesenian wayang, utamanya cerita-cerita dewa harus diubah dan diisi paham yang mengandung jiwa Islam dan membuang unsur-unsur kemusyrikan (Sunyoto, 2012: 136).

Transformasi wayang -baik segi cerita maupun pembangunan karakter tokoh- tentu merupakan sebuah tugas besar yang membutuhkan inovasi dan kecerdasan dalam mewujudkannya. Terlebih jika harus dihadapkan dengan fundamen cerita pewayangan yang berangkat dari epos Ramayana-Mahabarata Hindu membuat misi ini tidak bisa dibilang mudah. Pasalnya, kedua epos tersebut dipastikan memuat cerita para Dewa Hindu yang Islam justru memandangnya sebagai sesuatu yang sangat bertentangan dengan tauhid.

Para dewa dalam mitologi Hindu diyakini sebagi manifestasi, sinarnya Tuhan dalam fungsi tertentu. Oleh karena kekuasaan dan fungsi Tuhan demikian luas dan dalam, serta rumit, maka Tuhan mewujudkan diri dalam wujud dewa-dewa. Dengan kata lain, dewadewa adalah ciptaan Tuhan seakan-akan dewa-dewa itu terpisah dengan Tuhan, padahal sesungguhnya mereka adalah bagian integral dari kebesaran Tuhan (Jendra, 2003: 109). Ajaran dewa (henotheisme) inilah yang kemudian menjadi titik tolak antara nilai Islam dan Hindu yang begitu melekat pada kesenian wayang.

Kesakralan para Dewa dalam keyakinan masyarakat Jawa pra-Islam tersebut kemudian diatasi dan diterjemahkan melalui proses desakralisasi dengan melakukan inovasi fundamen pada gubahan silsilah. Silsilah (nasab) dalam pewayangan, meletakkan para Dewa Hindu dan karakter Dewa lain (yang baru dalam dunia wayang) pada garis keturunan Nabi Adam, yakni melalui jalur Nabi Sis. Adalah merupakan pondasi untuk melakukan desakralisasi terhadap simbol tertinggi agama Hindu sebagai keyakinan yang dipeluk oleh mayoritas masyarakat Jawa saat itu. Sebagaimana terpapar dalam bab sebelumnya, ketika dasar telah diletakkan, maka akan mudah bagi Walisongo untuk melancarkan berbagai gubahan-gubahan berikutnya -yang tentunya disesuaikan dengan Islam- agar tetap memposisikan wayang sebagai media hiburan yang efektif guna menginfiltrasi nilai-nilai tauhid ke dalam tatanan masyarakat.

Proses yang dikonstruksi oleh Walisongo bukan hanya sedang ingin melakukan tindakan memanusiakan manusia, tetapi tidak berlebihan jika desakralisasi melalui peletakan hirarki nasab pada para Dewa Hindu adalah upaya untuk memanusiakan para Dewa. Artinya jika dalam Brahman sebagai Tuhan alam semesta, bukan meletakkan para Dewa utamanya Trimurti- sebagai sebuah tatanan hirarki (atas-bawah) tetapi lebih kepada manifestasi dari wujudnya (sejajar), maka dalam wayang Dewa diletakkan pada posisi atas-bawah, tinggi-rendah, dahulu- 
belakangan, lama-baru, di bawah manusia pertama bernama Adam. Dengan kata lain Dewa-Dewa dalam pewayangan sedang mengalami desakralisasi karena otomatis mahluk yang lahir dari manusia, tentu dia adalah manusia juga apa pun itu namanya. Berikut ilustrasinya:

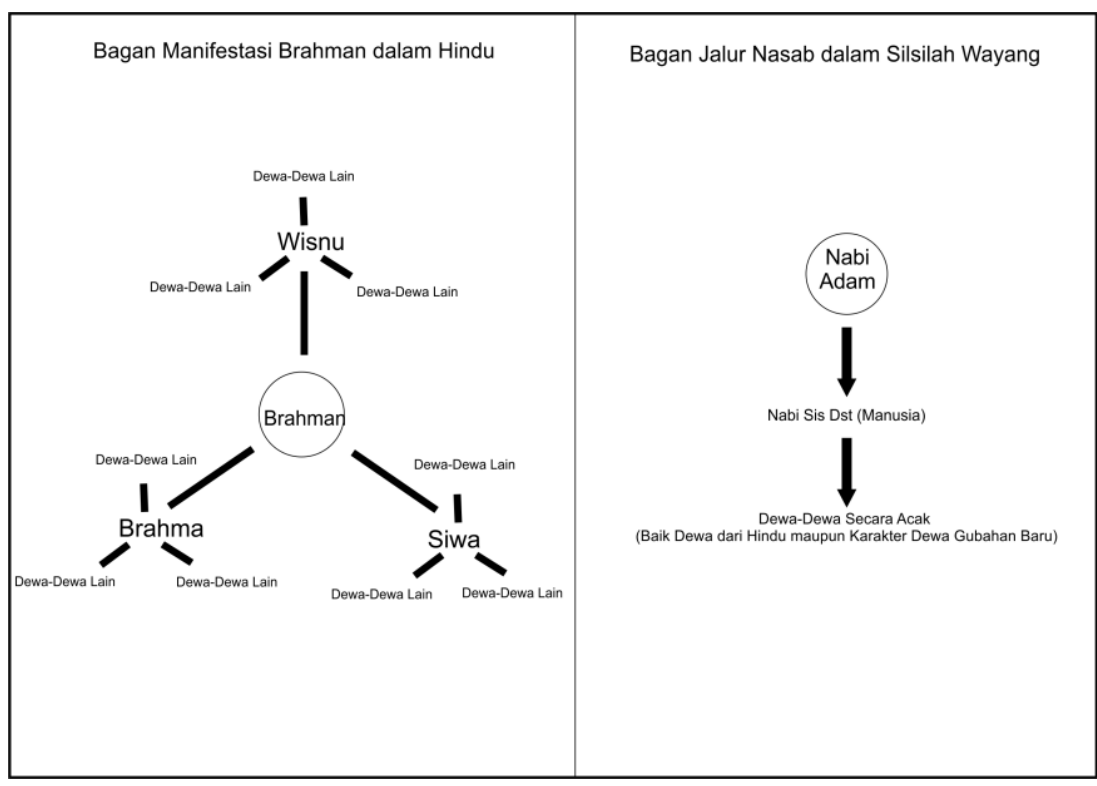

Gambar. 2. Ilustrasi Bagan Perbandingan antara manifestasi dan jalur nasab para Dewa versi ajaran Hindu dan Wayang Jawa

Setelah cukup jelas melihat perbandingan dua bagan di atas, maka pertanyaan baru yang muncul adalah perihal Nabi Sis yang dipilih oleh para Walisongo sebagai sandaran nasab dalam silsilah Wayang. Padahal dalam intern umat Islam kisah-kisah Nabi Sis -bahkan hingga saat inibelum begitu banyak diketahui. Masyarakat muslim justru lebih familiar dengan cerita Kabil-Habil sebagai cikal-bakal disyariatkannya ibadah Qurban. Lantas apa istimewa Nabi Sis sampai mendapat perhatian para Wali dalam rangka merekontruksi cerita pewayangan?.

Jawaban dari pertanyaan tersebut akan ditemukan mulai dengan meruntut kepada siapakah sebenarnya nasab Nabi Sis dan akan sampai hingga periode-periode berikutnya, yakni pada para Nabi yang masyhur -utamanya 25 Rasul- termasuk di dalamnya adalah Nabi Muhammad S.A.W. Nasab Nabi Muhammad S.A.W dapat diketahui sambung hingga Nabi Sis, sebagaimana berikut (al-Mubarakfury, 2012: 47-48):

Muhammad bin Abdullah bin Abdul Muthalib (Yang namanya Syibah) bin Hasyim (Yang namanya Amru) bin Abdu Manaf (Yang namanya 
Al-Mughirah) bin Qushay (Yang namanya Zaid) bin Kilab bin Murrah bin Ka'ab bin Lu'ay bin Ghalib bin Fihr (Yang berjuluk Quraiys dan menjadi cikal bakal nama kabilah) bin Malik bin An-Nadhr (Yang namanya Qais) bin Kinanah bin Khuzaimah bin Mudrikah (Yang namanya Amir) bin Ilyas bin Nizar bin Ma'ad bin Adnan bin Udad bin Hamaisa' bin Salaman bin Aush bin Bauz bin Qimwal bin Ubay bin Awwam bin Nasyid bin Haza bin Baldas bin Yaldaf bin Thabikh bin Jahim bin Nahisy bin Makhi bin Aidh bin Abqar bin Ubaid bin Ad-Da'a bin Hamdan bin Sinbar bin Yatsribi bin Yahzan bin Yalhan bin Ar'awy bin Aid bin Daisyan bin Aishar bin Afnad bin Aiham bin Muqshir bin Nahits bin Zarih bin Sumay bin Muzay bin Iwadhah bin Aram bin Qaidar bin Ismail bin Ibrahim bin Tarih (Yang namanya Azar) bin Nahur bin Saru' atau Sarugh bin Ra'u bin Falakh bin Aibar bin Syalakh bin Arfakhsyad bin Sam bin Nuh bin Lamk bin Matausyalakh bin Akhnukh bin Idris bin Yard bim Mahlail bin Qainan bin Yanisya bin Syaits (Sis) bin Adam.

Menarik kemudian ketika mengamati jalur nasab dari Nabi Muhammad Saw. yang berujung pada Nabi Sis untuk kemudian sampai pada Nabi Adam. Pemilihan Nabi Sis jika diamati tentu bukan hanya semata ingin melakukan desakralisasi terhadap fungsi Dewa-Dewa sebagai simbol tertinggi Agama Hindu, tetapi di saat yang sama juga sedang berlangsung proses sakralisasi terhadap sosok Nabi Muhammad -sebagai manusia utama panutan umat muslim - agar bisa diterima oleh masyarakat Jawa saat itu. Katakanlah Dewa dalam benak pemeluk Hindu menempati derajat yang begitu tinggi, maka jika para Dewa merupakan keturunan Nabi Sis, secara tidak langsung para Wali sedang menempatkan Nabi Muhammad pada posisi derajat tinggi ke dalam perspektif umat Hindu. Proses berikutnya yang diharapkan adalah ketika masyarakat Jawa pemeluk Hindu mengetahui bahwa Nabi Muhammad tidak kalah derajatnya dengan Dewa-Dewa mereka, sudah pasti proses internalisasi nilai Islam kepada mereka akan jauh lebih mudah.

Faktanya, cara yang dilakukan para Wali, terutama Sunan Kalijaga tidak sia-sia. Pendekatan budaya melalui proses akulturasi silsilah wayang membuahkan hasil yang signifikan terhadap perkembangan Islam, hingga kemudian Islam berkembang dengan pesat sampai kepelosok nusantara. Islam bukan lagi agama orang desa, Islam telah berhasil merambah sampai ke elit istana. Sisi persuasif dalam dakwah mereka adalah menjadi salah satu daya tarik bagi setiap orang saat itu (Saputra, 2010: 62). 


\section{KESIMPULAN}

Wayang sebagai manifesto kebudayaan Jawa nyatanya memang dikenal sebagai produk adaptif yang memiliki haluan besar garis cerita pada epos Hindu Ramayana dan Mahabharata. Artinya pada sisi fundamennya, wayang bahkan sarat akan ajaran Hindu yang berujung pada teologi politheisme. Kendati demikian Walisongo sebagai motor gerakan dakwah pada abad ke-14 di Tanah Jawa tidak lantas memberangus kesenian yang sarat akan makna, tapi melalui proses akulturasi. Justru kenyataan tentang adanya politheisme yang mendominasi gubahan cerita Ramayana dan Mahabharata, menjadi panggung bagi Walisongo, khususnya Sunan Kalijaga dalam melakukan improvisasi kesenian wayang secara kreatif dan inovatif. Cipta Rasa dan Karsa yang dihadirkan dalam kesenian wayang pada akhirnya menjadi pendobrak teologis masyarakat Jawa saat itu dengan menjadi media desakralisasi simbol politheisme tanpa adanya konflik. Satu dari banyak hal yang dilakukan adalah dengan melakukan restrukturisasi gubahan silsilah dewa Hindu yang berorientasi pada inti ajaran Trimurti, menjadi silsilah wayang yang berpusat pada Nabi Sis kemudian Nabi Adam yang merupakan representasi simbol tauhid bahwa tuhan tidak beranak dan diperanakan sesuai dengan ajaran yang ada di Al-Qur'an. Perubahan Silsilah Wayang dan Dakwah dilakukan secara persuasif oleh Walisongo tanpa sedikitpun memunculkan konflik di tengah masyarakat apalagi sampai adanya pertumpahan darah. 


\section{DAFTAR PUSTAKA}

Al-Mubarakfury dan Shafiyurrahman. 2012. Sirah Nabawiyah, Jakarta: Pustaka Al-Kautsar.

Dragon, M.S. 2016. The Great Tale of Prophet Adam and Prophet Jesus in Islam. Create Space: Scotts Valley, California,US.

Dwiandiyanta, B. Y., dkk. 2012. New Shadow Modeling Approach of Wayang Kulit. International Journal of Advanced Science and Technology Vol. 43, June, 2012.

Ensiklopdeia Umum Untuk Pelajar, 2005. Jakarta: PT Ichtiar Baru Van Hoeve.

Hardjana, A.M. 1993. Penghayatan Agama; Yang Otentik dan Tidak Otentik. Yogyakarta: Penerbit Kanisius.

Ilyas, D. 2016. Di Balik Kisah Adam AS: Menarik Nalar Makna Penciptaan, Palembang: e-Journal UIN Raden Fatah.

Ishomiddin. 2018. Pemikiran dan Filsafat Hukum Islam. Kencana Prenada Media Group: Jakarta Timur.

Jendra, I. W.2003. Teologi dan Etika Agama-Agama, Yogyakarta: Interfidei.

John, C.A dan Ryan, J.D. 2006. Encyclopedia of World Religion, Ensyclopedia of Hinduism, New York: Facts On File, Inc. An inmprint of Infobase Publishing.

Kapalaye, K.A. 2010. Kamus Pintar Wayang (Dari Versi India Hingga Pewayangan Jawa), Yogyakarta: Laksana.

Klostermaier, K.K. 2003. A Concise Encyclopedia of Hinduism. Oxford: Oneworld Publication.

Koentjaraningrat. 1977. Beberapa Pokok Antropologi Sosial. Jakarta: Dian Rakyat.

Mann, T. 2005. The Oxford Guide to Library Research. 3ed. New York, United States: Oxford University Press Inc.

Padmosoekotjo, S. 1979. Silsilah Wayang Purwa Mawa Carita Jilid. Surabaya: CV. Citra Jaya.

Purwadi. 1992. Wayang dan Filsafat Nusantara, Jakarta: CV. Haji Mas Agung.

Purwadi. 2003. Sejarah Sunan Kalijaga. Yogyakarta: Persada.

Rinehart, R. 2004. Contemporary Hinduism Ritual, Culture, and Practice. California: Library of Congress Cataloging-in-Publication Data. 
Samad, U.A. 1990. Agama-Agama Besar di Dunia terj. Great Religions of the World, Bombay: Mr. Abdur Razaak. Ebook-ww.aaiil.com.

Samovar, L.A., Etc. 2015. Communication Between Cultures , 9 ${ }^{\text {Th }}$ Edition, Boston: Cennage Learning.

Saputra, J.H. 2010. Mengungkap Perjalanan Sunan Kalijaga. Jakarta: Pustaka Media Press.

Slamet, Y.B.M. 2014. Constructing a Course on Indonesia Shadow Puppets for International Student, Celt, Volume 14, No. 1, July 2014.

Sou'yb, J. 1996. Agama-Agama Besar di Dunia. Jakarta: PT. Al Husna Zikra.

Sudjarwo, H.S., dkk. 2010. Rupa dan Karakter Wayang Purwa, Jakarta: Kaki Langit Kencana Prenada Media Group.

Suhardjono, L.A. 2016. Wayang Kulit And The Growth Of Islam In Java Humaniora. Vol. 7 No. 2 April 2016.

Sunyoto, A. 2012. Atlas Walisongo. Depok: Pustaka Iman.

Supriono, dkk. 2008. Pedhalangan Jilid 1. Jakarta: Departemen Pendidikan Nasional.

Sutiyono, 2013. Poros Kebudayaan Jawa, Yogyakarta: Graha Ilmu.

Yousof, G.S. 2010. Islamic Elements in Traditional Indonesian-Malay Theatre, Kajian Malaysia, Vol. 28, No. 1, 2010. 
